\title{
The study of glycerol-based fermentation and broth downstream by nanofiltration
}

\author{
Marek Gryta*, Agata Markowska-Szczupak, Joanna Grzechulska-Damszel, Justyna Bastrzyk, \\ Marta Waszak \\ West Pomeranian University of Technology, Szczecin, Institute of Chemical Technology and Environment Engineering \\ ul. Pułaskiego 10, 70-322 Szczecin, Poland \\ *Corresponding author: marek.gryta@zut.edu.pl
}

\begin{abstract}
In this work, the glycerol fermentation was carried out using Citrobacter freundii bacteria. The influence of glycerol and metabolites concentrations, and the $\mathrm{pH}$ changes on the efficiency of 1,3-propanediol production, during batch and fed-batch processes, was presented. The nanofiltration was used for the separation of obtained post-fermentation solutions. The resulted 1,3-PD solutions were significantly desalted, which may facilitate further downstream processes during 1,3-PD production.
\end{abstract}

Keywords: glycerol fermentation, 1,3-propanediol, nanofiltration, Citrobacter freundii.

\section{INTRODUCTION}

In 1995 the Shell company announced the commercialization of a new polyester $\left(\right.$ Corterra $^{\mathrm{TM}}$ PTT) based on terephthalic acid and 1,3-propanediol (1,3-PD). Poly(trimethylene terephthalate) (PTT) is a biodegradable polymer which founds great potential in textile, carpets and upholstery manufacturing. The market for 1,3-PD is currently over 100 million pounds per year and is still rapidly growing.

The majority of commercial synthesis of 1,3-propanediol are from acrolein by Degussa (now owned by DuPont, Wilmington, DE, USA) and from ethylene oxide by Shell. A recent application of 1,3-PD as a monomer for novel polyester and biodegradable plastics has led to a strong market need for the production of this bulk chemical preferably by a biological route. DuPont and its collaborator (Genencor) have developed a biocatalyst which would enable a fermentation-based process for the production of 1,3-PD' ${ }^{2}$. DuPont's polymerization plant in Decatur, Illinois (USA) has now successfully manufactured 1,3-PD from corn sugar. Their corn-based polymer, called Sorona $^{\mathrm{TM}}$, is more eco-friendly and has improved characteristics, such as softness, stretch recovery, vibrant colour and inherent stain resistance ${ }^{1}$.

1,3-PD is one of the oldest known fermentation products. It was reliably identified as early as in 1881 by August Freund, in a glycerol fermentation mixed culture containing Clostridium pasteurianum as an active organism. A more recent study revealed, that several other microorganisms, such as Clostridium butyricum, Citrobacter freundii, Klebsiella pneumoniae, and Enterobacter agglomerans are suitable for 1,3-PD production from glycerol ${ }^{1-15}$.

The production of biofuels, such as diester (biodiesel), generates glycerol (glycerin) as a main by-product. This common by-product represents 10 and $6 \%$ of the diester and ethanol productions, respectively. The utilization of a crude glycerol to produce 1,3-PD provides an area of opportunity where it would be possible to capitalize on the surplus of waste glycerol ${ }^{4,8,11}$.

The production of 1,3-propanediol from glycerol is generally performed under anaerobi conditions using glycerol as a sole carbon source. Under these conditions, a parallel pathway for glycerol operates which first pro- motes the glycerol oxidation to generate dihydroxyacetone (DHA), which was further metabolized through the glycolytic pathway with ethanol, acetic acid and lactate as by-products. The second pathway resulted in the dehydration of glycerol to generate 3-hydroxypropionaldehyde, which was then reduced to 1,3-propanediol, accounting for more than $50 \%$ of the glycerol consumed ${ }^{1,8-10}$.

The yield of 1,3-PD depends on the stoichiometry of reductive and oxidative pathways. If only 1,3-PD and acetic acid are formed, the yield of 1,3-PD is $67 \%$ (mol/ $\mathrm{mol}$ ) and for each acetic acid molecule formed is obtained two 1,3-PD molecules. However, all by-products are associated with a loss in 1,3-PD relative to acetic acid $^{1}$. A parameter very important that can affect 1,3- $\mathrm{PD}$ yield is $\mathrm{pH}^{10-14}$. The initial $\mathrm{pH}$ of culture medium is generally close to 7 , but the $\mathrm{pH}$ was reduced considerably below 5 after $24 \mathrm{~h}$ of fermentation due to formation of organic acids.

The fermentation conditions that enable the maximum concentration of 1,3-PD are accompanied by inhibition phenomena, notably by the fermentation products. The inhibition phenomenon induced by 1,3-propanediol has been attributed to an inhibitory effect of the diol function $^{15}$. The inhibitory effect of non-dissociated organic acids by the microorganisms is a well-known phenomenon and was demonstrated during the fermentation into 1,3$-\mathrm{PD}^{14,16}$. However, under favourable fermentation conditions ( $\mathrm{pH} 7$ ), these metabolites are practically always found in an anionic form as acetate and butyrate. The ranges of phenomena, such as the activating effect of acetate on growth or the influence of butyrate on the fermentation profile have been reported ${ }^{10,13}, 15$. During the preparation of culture media and fermentation, the acids produced were neutralized by the addition of sodium hydroxide. However, studies performed on Clostridium pasteurianum, $C$. botulinum and $C$. butyricum had shown that the sodium ion concentrations higher than $12 \mathrm{~g} / \mathrm{L}$ inhibited cell growth ${ }^{10,17}$. At concentrations lower than $12 \mathrm{~g} / \mathrm{L}$, the inhibitory effect of sodium ions was not pronounced. Fed-batch culture is commonly used in the microbial fermentation to achieve a high cell density because a substrate limitation or inhibition can be avoided by maintaining the medium substrate 
concentration at a relatively constant level during the cultivation.

The recovery of 1,3-PD from a complex and dilute fermentation broth has become a very important stage for the development of a commercially viable process. Due to several constraints, an efficient separation of 1,3-propanediol from a fermentation broth consisting of water, residual glycerol, glucose, by-products (acetic acid, lactic acid, succinic acid, ethanol, 2,3-butanediol), macromolecules (proteins, polysaccharides, and nucleic acid), salts, and residual medium components requires several integrated separation processes ${ }^{\mathbf{1 8}}$. Apart from the complexity of fermentation broth, a characteristics of 1,3-propanediol such as high boiling point $\left(214^{\circ} \mathrm{C}\right.$ at atmospheric pressure) and a strong hydrophilicity have become a technical hurdle for the development of an efficient purification process. The separation methods of 1,3-PD from a dilute solution by normal physical or complex extraction were not successful ${ }^{18,19}$. Although many solvent extractants are given in a patent, the hydrophilic 1,3-propanediol in a dilute broth fails to enter into the hydrophobic solvents, except when a large amount of solvents is added into a concentrated broth.

Vacuum distillation is preferred over traditional distillation as it saves energy due to lowering the boiling point. However, desalination and deproteinization are required before the evaporation that makes the entire process complicated and non-profitable. The application of consecutive stages: removal of biomass, removal of proteins, concentration of broth, and separation of 1,3-PD by silica gel chromatography allows to achieve the effective separation of 1,3-propanediol from fermentation broth $^{18}$. However, a decrease of the $\mathrm{pH}=4$ for efficient separation is required.

The residual salts adversely affect the purification of 1,3-PD, therefore the broth desalination is always needed as a pretreatment. An electrodialysis was found to be an efficient way for salts removal and the recovery from fermentation broth ${ }^{\mathbf{2 0}}$. The nanofiltration (NF) is other effective process that can be used for broth desalination ${ }^{21}$. The NF membranes have a surface charge, which depends on the $\mathrm{pH}$ of solution. The salts rejection is maximal over the membrane isoelectric point, primarily due to decreased electrostatic repulsion ${ }^{21-24}$.

The objective of the present study was to evaluate the changes of fermentation parameters on the efficiency of both 1,3 PD production and broth downstream separation by NF process. The study was carried out with broths, which was prepared using Citrobacter freundii bacteria for the fermentation of glycerol solutions.

\section{EXPERIMENTAL}

In the study the glycerol solutions were fermented using Citrobacter freundii bacteria isolated and characterized in Department of Biotechnology and Food Microbiology, Poznań University of Life Science, Poland.

Batch and fed-batch bioreactor fermentations were conducted in a LiFlusGX bioreactor (Biotron Inc., Korea), the working volume of which was adjusted at $2 \mathrm{~L}$. Before experimental use, strain was pre-cultured in the MRS medium (BTL, Poland) and incubated at $30^{\circ} \mathrm{C}$ for 24 h. Fresh cultures of Citrobacter freundii under sterile conditions were inoculated to the bioreactor (bacteria comprise $5 \%$ of the total reactor's volume). The medium (broth) for the fermentation process besides the glycerol in 1 litre of distilled water also contains: $3.4 \mathrm{~g} \mathrm{~K}_{2} \mathrm{HPO}_{4}$;

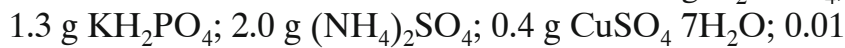
$\mathrm{g} \mathrm{CaCl}_{2} \cdot 2 \mathrm{H}_{2} \mathrm{O} ; 0.004 \mathrm{~g} \mathrm{CoCl}_{2} \cdot 6 \mathrm{H}_{2} \mathrm{O} ; 2.0 \mathrm{~g}$ yeast extract, $2.5 \mathrm{~g}$ peptone $\mathrm{K}$ and $1.5 \mathrm{~g}$ meat extract. The broths were supplemented in glycerol to obtain the concentrations in the range of $20-100 \mathrm{~g} / \mathrm{dm}^{3}$. The agitation rate was $150 \pm 5 \mathrm{rpm}$, the incubation temperature was $30^{\circ} \mathrm{C}$. The study was carried out with and without $\mathrm{pH}$ adjustment. In the case of $\mathrm{pH}$ adjustment, the $\mathrm{pH}$ was maintained at 7.0 by an automatic addition of $5 \mathrm{M} \mathrm{NaOH}$.

Broth samples were collected every $24 \mathrm{~h}$ and plated on MRS agar (BTL, Poland). Serial dilutions were prepared if necessary in $\mathrm{NaCl}$ solution $(0.9 \%)$ and the samples were then plated on MRS agar. The plates were incubated for $24 \mathrm{~h}$ at $30^{\circ} \mathrm{C}$ and the colony-forming units (CFUs) were then counted.

In a fed-batch fermentation, the glycerol concentration was initially at 10,20 or $50 \mathrm{~g} / \mathrm{L}$ and after $24 \mathrm{~h}$ of the process was below $5 \mathrm{~g} / \mathrm{L}$, therefore, a new portion of glycerol was added into the medium.

The fermentation broths were separated using a NF270 membrane from Dow FilmTec (Minneapolis, USA). The NF experiments were carried out in a laboratory-scale test cell using a SEPA-CFII (GE Osmonics, USA) cross-flow module. An active membrane area was $150 \mathrm{~cm}^{2}$. The volume of the feed tank was 3 L. Each process with a given solution was repeated twice or three times. The transmembrane pressure amounted to $1.0 \mathrm{MPa}$, and temperature was set at $298 \mathrm{~K}( \pm 1 \mathrm{~K})$. The samples from both permeate and retentate flows were collected at $30 \mathrm{~min}$ intervals. The experiments were carried out using the feed flow at a level of $0.498 \mathrm{~m}^{3} / \mathrm{h}$.

The determination of separated solution compositions was performed using a high-performance liquid chromatograph HPLC UlitiMate 3000 (Dionex, USA) with refractometer detector RI-101 (Shodex) and a column HyperREZ XP H (Thermo Scientific, USA), through which a $\mathrm{H}_{2} \mathrm{SO}_{4}$ solution $(0.005 \mathrm{M})$ flowed $\left(0.6 \mathrm{~mL} \mathrm{~min}^{-1}\right)$.

\section{RESULTS AND DISCUSSION}

\section{Batch fermentation}

In some cases, the effectiveness of used separation method of 1,3-PD is increased when the $\mathrm{pH}$ value of post-fermentation broth is reduced to a level of $4-5^{\mathbf{1 8}}$. As a rule, this requires the addition of acid into the broth, because a value of $\mathrm{pH}=7$ is maintained during the fermentation by dosing an $\mathrm{NaOH}$ solution, ${ }^{\mathbf{4}} \mathbf{1 1}, \mathbf{1 8}$. However, the salt concentration in the broth is increased as a result of adding base and acid, what hinders the operation of downstream separation. For this reason it would be advantageous to carry out the glycerol batch fermentation without the introduction of additional solutes.

However, the performed studies demonstrated, that using a batch fermentation, it is difficult to obtain a high degree of glycerol fermentation and the final concentration of 1,3-PD did not exceed $5 \mathrm{~g} / \mathrm{L}$ (Fig. 1). A similar concentration of 1,3-PD and the final $\mathrm{pH}$ of broth equal 


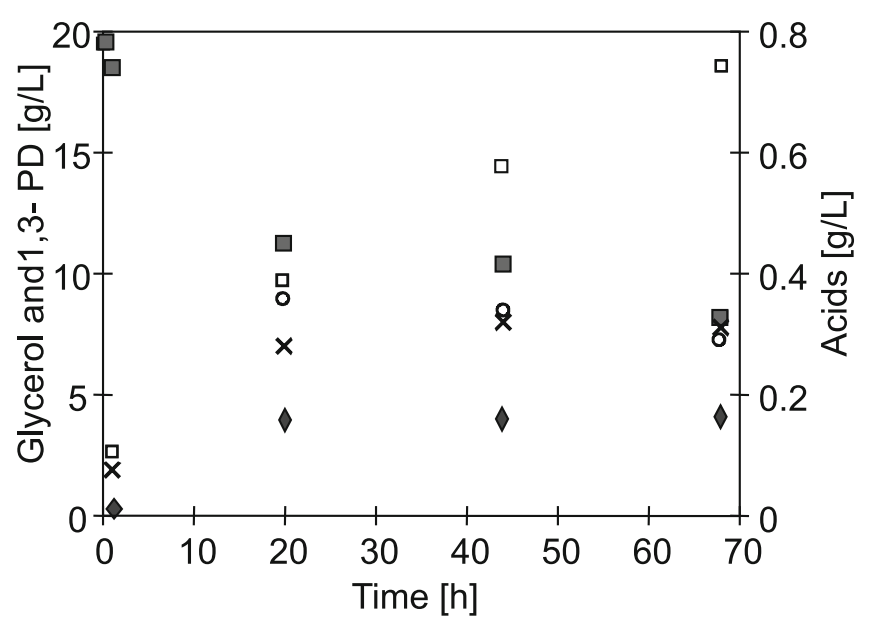

Figure 1. Batch fermentation of glycerol $(20 \mathrm{~g} / \mathrm{L})$ without $\mathrm{pH}$ adjustment. - glycerol, $-1,3-\mathrm{PD}$ and acids: $\square$ - acetic, $\bigcirc$ - lactic, $\mathrm{x}$ - succinic

to 5.25 was obtaining using the strain Citrobacter freundii ATCC 8090 for the fermentation a crude glycerol $20 \mathrm{~g} /$ $\mathrm{L}^{8}$. In our case the $\mathrm{pH}$ value decreased to 4.8 (Fig. 2) and the production of 1,3-PD practically was eliminated after $24 \mathrm{~h}$ of fermentation (Fig. 1). A slight decline of glycerol concentration observed during the next two days was associated with the formation of the carboxylic acids, mainly acetic acid, the final concentration of which amounted to $0.73 \mathrm{~g} / \mathrm{L}$. The increase of initial glycerol concentration from 20 to $50 \mathrm{~g} / \mathrm{L}$ did not improve the 1,3-PD production, and on the contrary, the obtained concentration of 1,3-PD was less than $2 \mathrm{~g} / \mathrm{L}$ (Fig. 3). It was probably resulted from the inhibition by a substrate, what hindered the bacteria growth, the amount of which was decreased from 7.14 to $4 \log$ CFU during the consecutive days of process (Fig. 2). In the case of glycerol solution equal to $20 \mathrm{~g} / \mathrm{L}$, this amount increased from 7.8 to $14.5 \log$ CFU during three days of studies. A larger resistivity to high glycerol concentrations exhibited strain C. freundii FMCC-B 294 (VK-19) ${ }^{14}$. However, a significant decrease of the specific growth rate was also observed in this case, when the initial glycerol concentration was higher than $20 \mathrm{~g} / \mathrm{L}$.

A much larger resistivity of bacteria on the fermentation conditions was obtained when the $\mathrm{pH}$ value was maintained at a level of 7 . Under these conditions, the

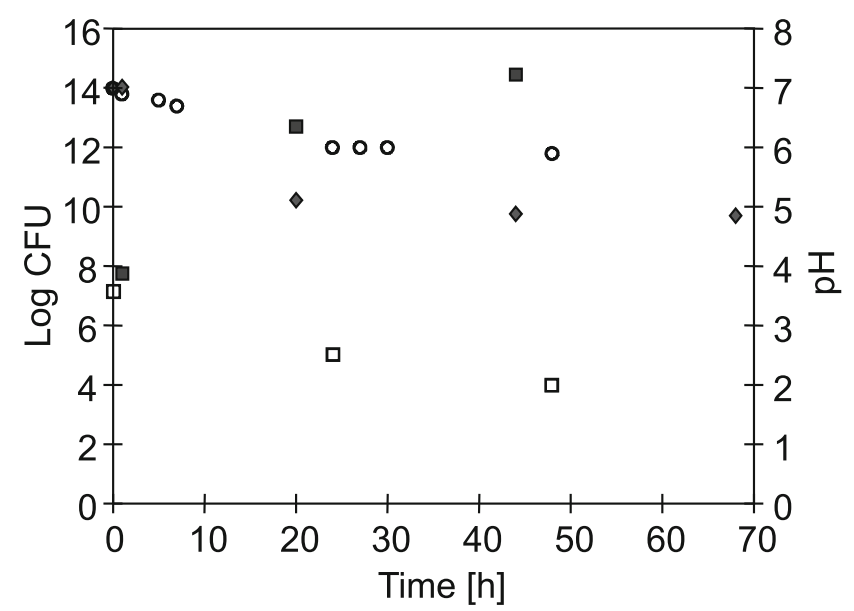

Figure 2. Batch fermentation of glycerol without $\mathrm{pH}$ adjustment. Glycerol $20 \mathrm{~g} / \mathrm{L}$ : - pH. $\square-\log$ CFU. Glycerol $50 \mathrm{~g} / \mathrm{L}: \bigcirc-\mathrm{pH}, \square-\log \mathrm{CFU}$

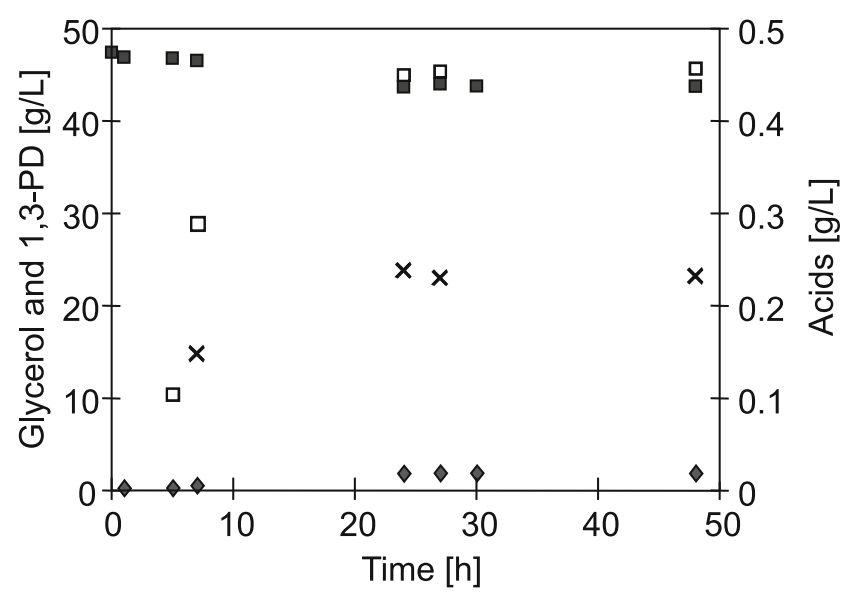

Figure 3. Batch fermentation of glycerol $(50 \mathrm{~g} / \mathrm{L})$ without $\mathrm{pH}$ adjustment. - 1,3-PD, $\mathbf{\square}$ - glycerol; acids: $\square$ acetic, $\mathrm{x}$ - succinic

fermentation proceeded better than for the above-presented cases without the $\mathrm{pH}$ control even for the initial glycerol concentration amounting $100 \mathrm{~g} / \mathrm{L}$. However, a high glycerol concentration prolonged the adoption period of bacteria and after the first $22 \mathrm{~h}$, their amount was only increased from 4.1 to $5.9 \log$ CFU. However, after the consecutive $44 \mathrm{~h}$ of fermentation process, this amount reached a value of $16.7 \log$ CFU. After $70 \mathrm{~h}$ of process, the broth contained $22.8 \mathrm{~g} / \mathrm{L}$ of $1,3-\mathrm{PD}$, and the final glycerol concentration amounted to $35.2 \mathrm{~g} / \mathrm{L}$ (Fig. 4).

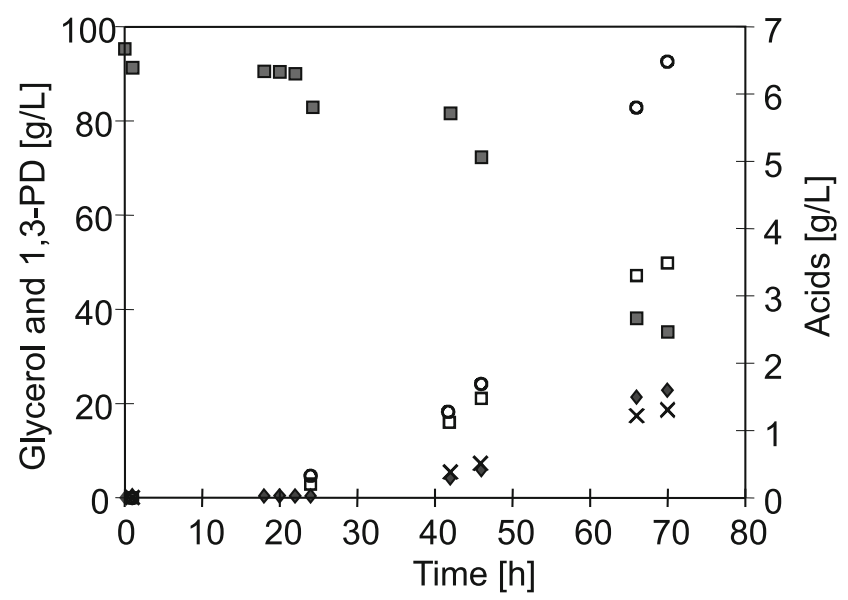

Figure 4. Batch fermentation of glycerol $(100 \mathrm{~g} / \mathrm{L})$ with $\mathrm{pH}$ adjustment. - glycerol, $-1,3-\mathrm{PD}$ and acids: $\square$ - acetic, $\bigcirc$ - lactic, $x$ - succinic

A prolongation of fermentation by at least a consecutive day could be required in order to decrease this concentration. In other work, the final 1,3-PD concentration of $45.9 \mathrm{~g} / \mathrm{L}$ was achieved for initial glycerol concentration of $100 \mathrm{~g} / \mathrm{L}$, but the maximum productivity of $1.53 \mathrm{~g} /(\mathrm{L} \mathrm{h})$ was observed at a $80 \mathrm{~g} / \mathrm{L}$ glycerol concentration ${ }^{4}$.

The studies demonstrated that a decrease of the initial glycerol concentration in the broth to a level of $20 \mathrm{~g} / \mathrm{L}$ allows to increase the effectiveness of batch fermentation. When three consecutive fermentations were carried out for $24 \mathrm{~h}$ (Fig. 5), the total amount of 1,3-PD equal to $27 \mathrm{~g}$ was obtained from $60 \mathrm{~g}$ of glycerol, hence, a larger amount than that for a single fermentation with 100 $\mathrm{g} / \mathrm{L}$ of glycerol (Fig. 4). Moreover, a very important is fact, that almost the complete fermentation of glycerol was achieved, when a lower initial concentration was 


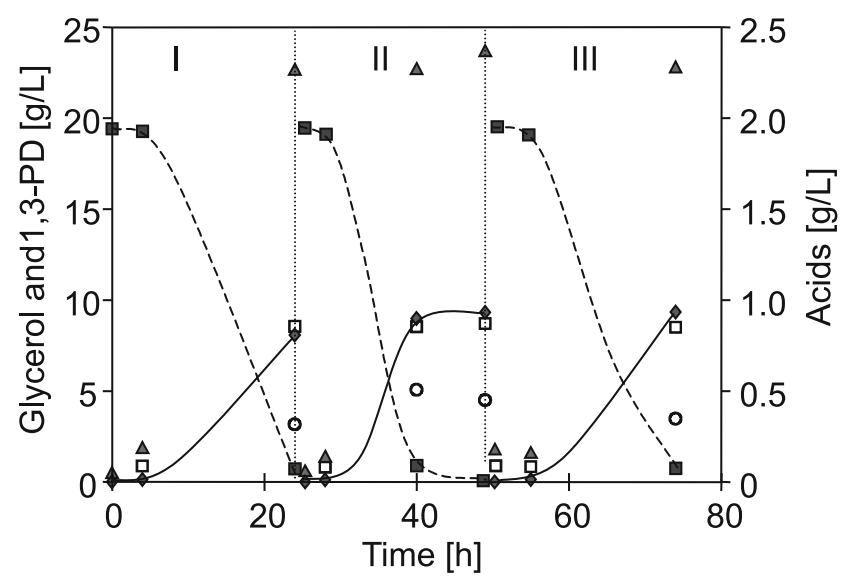

Figure 5. Three (I-III) one day batch fermentation of glycerol $(20 \mathrm{~g} / \mathrm{L})$ with $\mathrm{pH}$ adjustment. $\mathbf{\square}$ - glycerol, $-1,3$ -PD and acids: $\Delta$ - acetic, $\bigcirc$ - lactic, $\square$ - succinic

used. This is very important because when the glycerol is fermented the separation of 1,3-PD by nanofiltration method is significantly improved and the raw material losses are reduced ${ }^{21}$.

The obtained results confirmed that the fermentation conditions which enable to obtain the maximum concentration of 1,3-PD are also accompanied by inhibition phenomena, notably, by the fermentation products, such as 1,3-PD and the carboxylic acids. The inhibitory effect of non-dissociated organic acids by the microorganisms is a well-known phenomenon and was demonstrated during the fermentation to produce 1,3-propanediol. However, under favourable fermentation conditions $(\mathrm{pH}=7)$, these metabolites are practically always found in an anionic form as acetate and lactate ${ }^{7}$. This improved the separation by NF process.

\section{Fed-batch fermentations}

Fed-batch culture is commonly used in a microbial fermentation to achieve a high cell density because the substrate limitation or inhibition can be avoided by maintaining the medium substrate concentration at a relatively constant level during the cultivation. However, the performed studies demonstrated that after the fermentation of $50 \mathrm{~g} / \mathrm{L}$ of glycerol, the number of bacteria cells started to decrease, what slowed down the fermentation during the consecutive days of process (Fig. 6). This probably resulted from a high concentration of products $(30 \mathrm{~g} / \mathrm{L}$

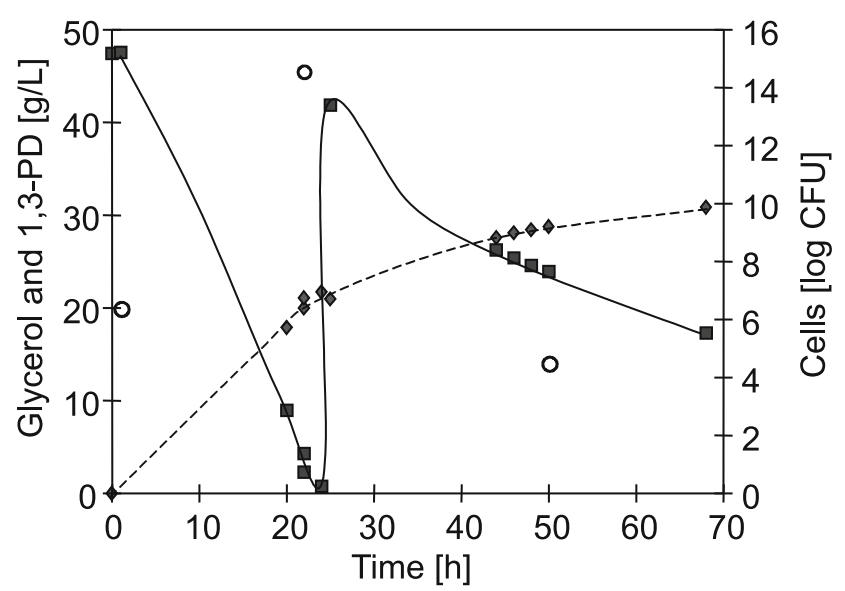

Figure 6. Three days fed-batch fermentation of glycerol with pH adjustment. - glycerol, $\bullet-1,3-\mathrm{PD}$ and $\mathrm{O}-\log \mathrm{CFU}$

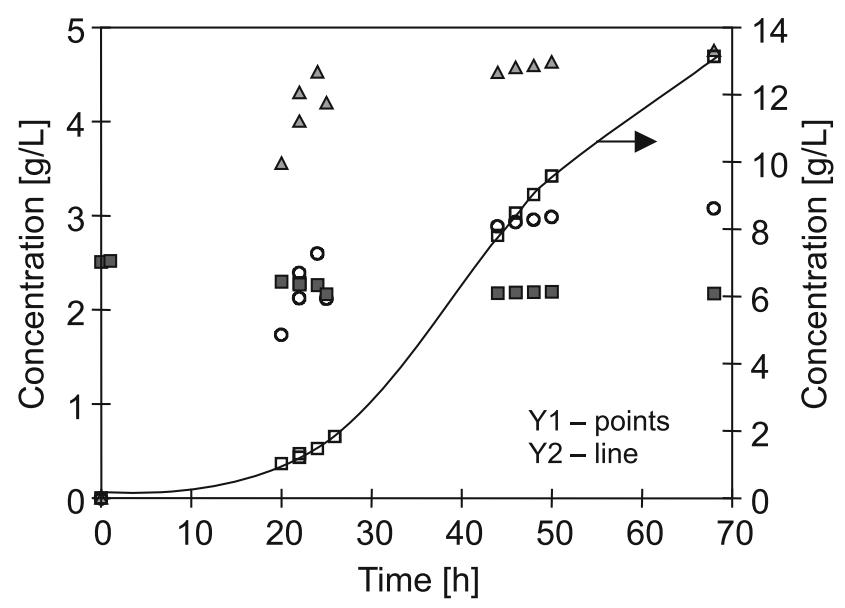

Figure 7. Three days fed-batch fermentation of glycerol with $\mathrm{pH}$ adjustment. Acids: $\wedge$ - succinic, $\bigcirc$ - tartaric, $\square$ - lactic, $\mathbf{\square}$ - acetic

1,3-PD) and the total concentration of carboxylic acids higher than $20 \mathrm{~g} / \mathrm{L}$ (Fig. 7).

A high number of cells at a level of $16 \log$ CFU was maintained for more than three days by using a lower dosing of glycerol (Fig. 8). However, such a procedure prolongs the process time. After $80 \mathrm{~h}$, it was fermented in total $50 \mathrm{~g} / \mathrm{L}$ of glycerol obtaining about $18 \mathrm{~g} / \mathrm{L}$ 1,3-PD, hence, a smaller amount than that in the case when the initial concentration of $50 \mathrm{~g} / \mathrm{L}$ was used (Fig. 6). Moreover, in this case, the amount of formed carboxylic acids was slightly increased when glycerol dosing was slower (Fig. 9).

In the case of fermentation carried out by a fed-batch method without $\mathrm{pH}$ control, the 1,3-PD content exceeding $8 \mathrm{~g} / \mathrm{L}$ was obtained after the consumption of about $20 \mathrm{~g} / \mathrm{L}$ of glycerol. Hence, better results were obtained in a comparison with the fermentation of batch type for the initial glycerol concentration of $20 \mathrm{~g} / \mathrm{L}$ (Fig. 1). However, the process was carried out for almost $100 \mathrm{~h}$, what has an unfavourable effect on its effectiveness.

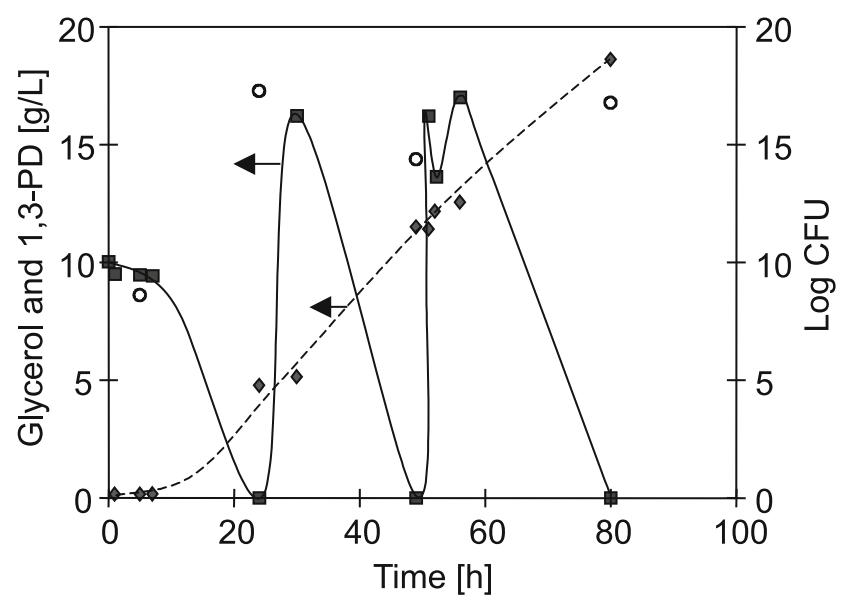

Figure 8. Four days fed-batch fermentation of glycerol with $\mathrm{pH}$ adjustment. $\square-$ glycerol, $\bullet-1,3-\mathrm{PD}$ and $\bigcirc-\log$ CFU

\section{Nanofiltration}

The conventional evaporation and distillation techniques normally used in the removal of water and purification of 1,3-propanediol suffer from a problem of high energy consumption, leading to a high cost of the target product. Vacuum distillation would save energy due to a decline of the boiling points. However, the traditional 


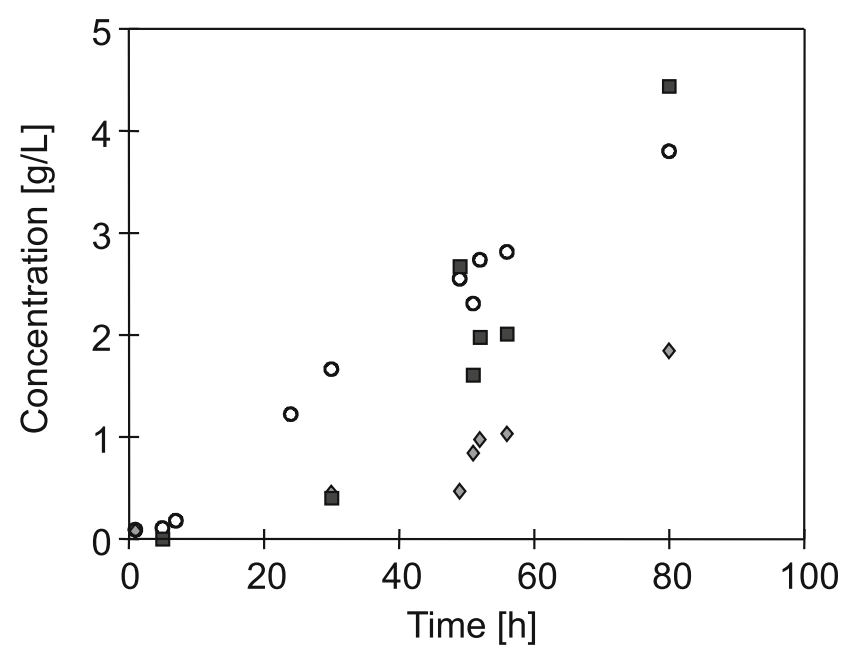

Figure 9. Four days fed-batch fermentation of glycerol with pH adjustment. Acids: $\bigcirc$ - acetic $\bullet-$ succinic, - lactic

vacuum distillation method for the recovery and purification of 1,3-propanediol causes several problems. For example, the denaturation of macromolecules makes broth become very viscous and the salts in the broth are crystallized out after the condensation, which lead to a low evaporation efficiency.

A significant desalination of broth and a partial separation of organic compounds can be achieved in the nanofiltration process. Independently on the process conditions and a kind of membrane used, it can be expected, that the salts present in the broth will be retained by more than $60 \%$. During the separation of studied broths by NF270 membrane the retention of the monovalent ions was close to $80 \%$, while that of the multivalent ions was higher than $94 \%$ (Fig. 11). The study revealed that the retention of 1,3-PD was several times lower, what permitted to separate this diol into the permeate. As a result, the NF pre-treatment enables a further application of evaporation method without problems associated with the presence of salts.

The $\mathrm{pH}$ value affects significantly both the desalination of ionic solutes, and the degree of separation in the NF process. The retention of salt and the carboxylic acids exceeding $90 \%$ was obtained for the broths with the $\mathrm{pH}$ value equal to 7 . The retention of 1,3-PD was below $20 \%$, thus the NF270 membrane permits enrichment

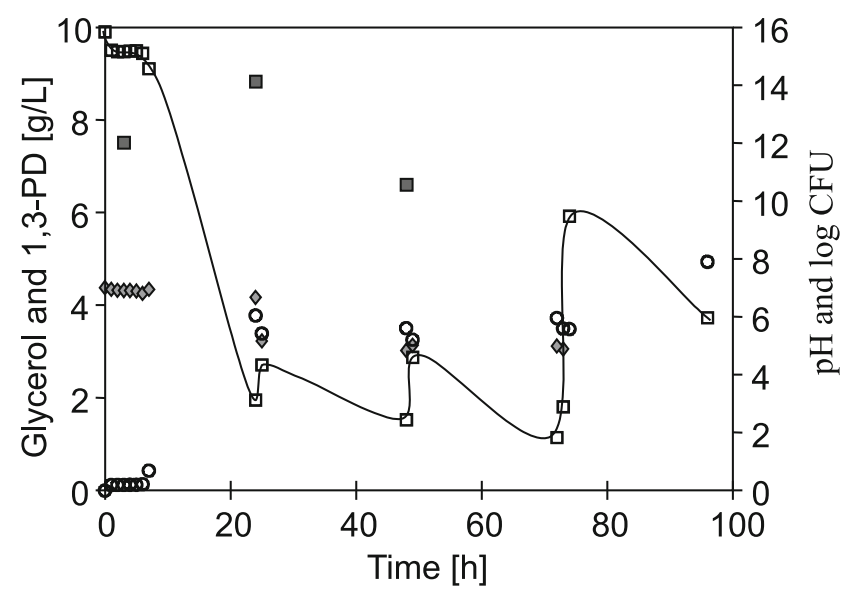

Figure 10. Four days fed-batch fermentation of glycerol without $\mathrm{pH}$ adjustment. $\square-$ glycerol, $\circ-1,3-\mathrm{PD},-\mathrm{pH}$ and - $-\log \mathrm{CFU}$

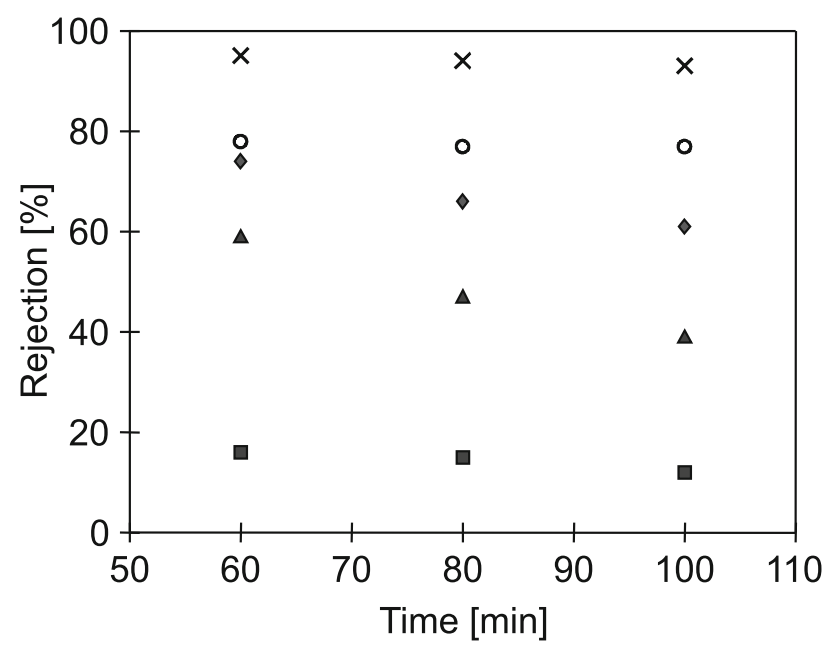

Figure 11. Nanofiltration of post-fermented glicerol solution $(\mathrm{pH}=4)$. Membrane NF270, TMP $=1.0 \mathrm{MPa}$. - 1,3-PD, $\mathrm{x}-\mathrm{PO}_{4}^{-3}, \circ-\mathrm{Na}^{+}$and acids: - lactic, $\Delta-$ succinic

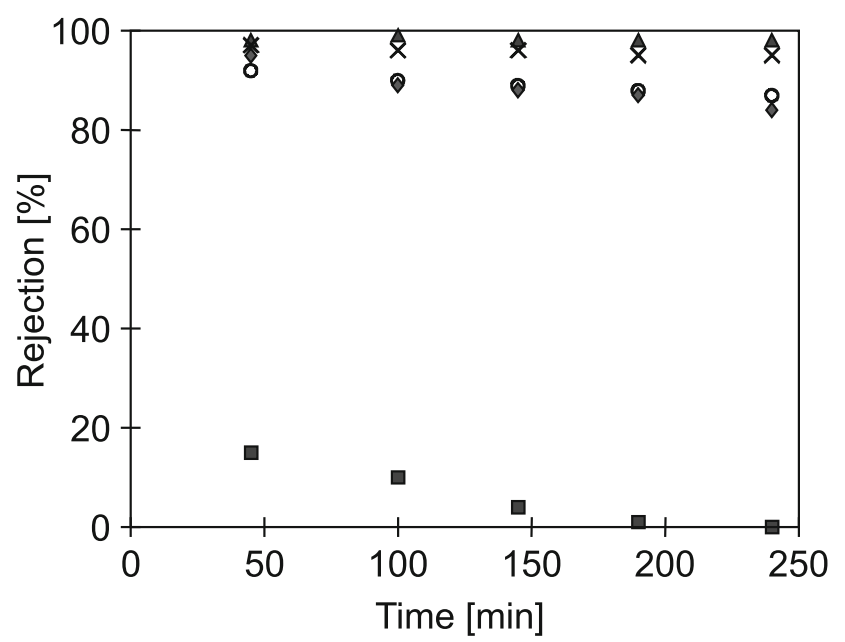

Figure 12. Nanofiltration of post-fermented glicerol solution $(\mathrm{pH}=7)$. Membrane NF270, TMP $=1.0 \mathrm{MPa}$. - 1,3-PD, $\mathrm{x}-\mathrm{PO}_{4}^{-3}, \mathrm{O}-\mathrm{Na}^{+}$and acids: - lactic, $\Delta-$ succinic

of the permeate in this diol (Fig.12). The NF process was carried out in a batch mode, and the feed was continuously concentrated. Due to the increase of the ions concentration, the rejection coefficient was slowly decreased (Figs. 11 and 12). In the case of broth with $\mathrm{pH}=7$ for all solutes the rejection exciding $80 \%$ was maintained, beside the 1,3-PD, which rejection decreases to almost zero. This situation is very advantageous, because allows to separate the diol from broth and to limit the content of impurities remaining in the permeate.

\section{CONCLUSIONS}

The performed research confirmed that except 1,3-PD, the other metabolites (mainly carboxylic acids) are produced during the glycerol fermentation with Citrobacter freundii bacteria. The majority of the products were formed during the first two days, and a prolongation of process over the next days did not cause the major changes. Therefore, due to the inhibitory effect, the application of fed-batch method is also limited. A continuous fermentation process can be conducted only if metabolites will be separated selectively. 
It was demonstrated that a one-day fermentation with $\mathrm{pH}$ adjustment $(\mathrm{pH}=7)$ enables to improve the glycerol fermentation process.

The obtained results demonstrated that NF process allows to separate the post-fermented glycerol solution into several fractions, which should facilitate the down-stream treatment of solution obtained from bioreactor.

\section{ACKNOWLEDGMENT}

The studies were performed within the framework of project no. 01.01.02-00-074/09 co-founded by the European Union from European Regional Development Founds within the framework of the Innovative Economy Operational Programme 2007-2013.

\section{LITERATURE CITED}

1. Saxena, R.K., Anand, P., Saran, S. \& Isar, J. (2009). Microbial production of 1,3-propanediol: Recent developments and emerging opportunities. Biotechnol. Adv. 27, 895-913. DOI: 10.1016/j.biotechadv.2009.07.003.

2. Nakamura, Ch.E. \& Whited, G.M. (2009). Metabolic engineering for the microbial production of 1,3-propanediol. Curr. Opin. Biotechnol. 14, 454-459. DOI: 10.1016/j. copbio.2003.08.005.

3. Raynaud, C., Sarcabal, P., Meynial-Salles, I., Croux, Ch. \& Soucaille, P. (1993). Molecular characterization of the 1,3-propanediol (1,3-PD) operon of Clostridium butyricum. Appl. Microbiol. Biotechnol. 38, 453-457. DOI: 10.1073_pnas.0734105100.

4. Metsoviti, M., Zeng, An.P., Koutinas, A.A. \& Papanikolaou, S. (2013). Enhanced 1,3-propanediol production by a newly isolated Citrobacter freundii strain cultivated on biodiesel-derived waste glycerol through sterile and non-sterile bioprocesses. J. Biotechnol. 163, 408-418. DOI: 10.1016/j.jbiotec.2012.11.018.

5. Anand, P. \& Saxena, R.K. (2012). A comparative study of solvent-assisted pretreatment of biodiesel derived crude glycerol of growth and 1,3-propanediol production from Citrobacter freundii. New Biotechol. 29, 199-205. DOI: 10.1016/j.nbt.2011.05.010.

6. Boenigk, R., Bowien, S. \& Gottschalk, G. (1993). Fermentation of glycerol to 1,3-propanediol in continuous cultures of Citrobacter freundii. Appl. Microbiol. Biotechnol. 38, 453-457. DOI: 10.1007/BF00242936.

7. Colin, T., Bories, A., Lavigne, C. \& Moulin, G. (2001). Effects of Acetate and Butyrate During Glycerol Fermentation by Clostridium butyricum. Curr. Microbiol. 43, 238-243. DOI: 10.1007/s002840010294.

8. Ferreira, T.F., Ribeiro, R.R., Ribeiro, C.M.S., Freire, D.M.G. \& Coelho, M.A.Z. (2012). Evaluation of 1,3-Propanediol Production from Crude Glycerol by Citrobacter freundii ATCC 8090. Chem. Engin. Transactions. 27, 157-162. DOI: 10.3303/CET1438080.

9. Barbirato, F., Grivet, J.P., Soucaille, P. \& Bories, A. (1996). 3-Hydroxypropionaldehyde, an Inhibitory Metabolite of Glycerol Fermentation to 1,3-Propanediol by Enterobacterial Species. Appl. Environ. Microbiol. 62(4), 1448-1451.

10. Tomczak, W. \& Gryta, M. (2013). The application of ultrafiltration for separation of glycerol solution fermented by bacteria. Pol. J. Chem. Tech. 15(3), 115-120. DOI: $10.2478 /$ pjct-2013-0057.
11. Barbirato, F., Himmi, El H., Conte, T. \& Bories, A. (1998). 1,3-propanediol production by fermentation: An interesting way to valorize glycerin from the ester and ethanol industries. Ind. Crops Prod. 7, 281-289. DOI: 10.1016/S0926-6690(97)00059-9.

12. Yanga, Ch., Jianga, P., Xiaoa, S., Zhanga, Ch., Loub, K. \& Xinga, X.H. (2011). Fed-batch fermentation of recombinant Citrobacter freundii with expression of a violacein-synthesizing gene cluster for efficient violacein production from glycerol. Biochem. Eng. J. 57, 55-62. DOI:10.1016/j.bej.2011.08.008.

13. Russel, J.B. (1992). Another explanation for the toxicity of fermentation acids at low $\mathrm{pH}$ : anion accumulation versus uncoupling. J. Appl. Bacteriol. 73, 363-370. DOI: 10.1111/j.1365-2672.1992.tb04990.x.

14. Biebl, H. (1991). Glycerol fermentation of 1,3-propanediol by Clostridium butyricum. Measurement of product inhibition by use a pH-auxostat. Appl Microbiol. Biotechnol. 35, 701-705. DOI: 10.1007/BF00169880.

15. Colin, T., Bories, A. \& Moulin, G. (2000). Inhibition of Clostridium butyricum by 1,3-propanediol and diols during glycerol fermentation. Appl. Microbiol. Biotechnol. 54, 201-205. DOI: 10.1007/s002530000365.

16. Zeng, A.P., Ross, A., Biebl, H., Tag, C., Günzel, B. \& Deckwer, W.D. (1994). Multiple product inhibition and growth modeling of Clostridium butyricum and Klebsiellia pneumoniae in glycerol fermentation. Biotechnol. Bioeng. 44, 902-911. DOI: 10.1002/bit.260440806.

17. Homann, T., Tag, C., Biebl, H., Deckwer, W.D. \& Schink, B. (1990). Fermentation of glycerol by Klebsiella and Citrobacter strains. Appl. Microbiol. Biotechnol. 33, 121-126. DOI: 10.1007/BF00176511.

18. Annand, P., Saxena, R.K. \& Marwah, R.G. (2011). A novel downstream process for 1,3-propanediol from glycerol-based fermentation. Appl. Microbiol. Biotechnol. 90, 1267-1276. DOI: 10.1007/s00253-011-3161-2.

19. Anand, P. \& Saxena, R.K. (2012). A comparative study of solvent-assisted pretreatment of biodiesel derived crude glycerol of growth and 1,3-propanediol production from Citrobacter freundii. New Biotechol. 29, 199-205. DOI: $10.1016 /$ j.nbt.2011.05.010.

20. Wu, R.Ch., Ren, H.J., Xu, Y. \& Liu, D. (2010). The final recover of salt from 1,3-propanadiol fermentation broth. Sep. Purif. Technol. 73, 122-125. DOI: 10.1016/j. seppur.2010.03.013.

21. Bastrzyk, J., Gryta, M. \& Karakulski, K. (2014). Fouling of nanofiltration membranes used for separation of fermented glycerol solutions. Chem. Pap. 68 (6), 757-765. DOI: 10.2478/s11696-013-0520-8.

22. Himstedt, H.H., Marshall, K.M. \& Wickramasinghe, S.R. (2011). pH-responsive nanofiltration membranes by surface modification. J. Membr. Sci. 366, 373-381. DOI: 10.1016/j.memsci.2010.10.027.

23. Luo, J., \& Wan, Y. (2011). Effect of highly concentrated salt on retention of organic solutes by nanofiltration polymeric membranes. J. Membr. Sci. 372, 145-153. DOI: 10.1016/j.memsci.2011.01.066.

24. Mohammad, A.W., Basha, R.K. \& Leo, C.P. (2010). Nanofiltration of glucose solution containing salts: Effects of membrane characteristics, organics component and salts on retention. J. Food Eng. 97, 510-518. DOI: 10.1016/j.jfoodeng.2009.11.010. 